\title{
1 \\ Purpose, approach and outline of the book
}

\subsection{PURPOSE OF THE BOOK}

EU climate law can be defined as all European Union legislation related to climate action. It is one of the most dynamic and fastest growing areas of EU law. This is perhaps best exemplified by the Union's recent efforts to establish a 'European Climate Law' that intends to present a legal framework for achieving climate neutrality in the EU by $2050 .{ }^{1}$

In general, a distinction can be made between climate mitigation law and climate adaptation law. The former focuses on the reduction ('mitigation') of greenhouse gas emissions to curb global warming, while the latter concerns the adjustment of society ('adaptation') to the consequences of global warming. Climate mitigation law thus addresses the causes of climate change, for instance by pricing carbon and by requiring a higher share of renewable energy. Climate adaptation law fights the consequences of climate change, for instance by building more flood defences.

The purpose of our book is to provide an introduction to EU climate mitigation law. We focus on mitigation law for the following four reasons. First, mitigation measures are typically defined at EU level, whereas adaptation measures are mostly constructed at (sub-)national level. Second, in the period 2021-30, mitigation requires considerably higher extra investment from the EU budget than does adaptation. ${ }^{2}$ Third, mitigation will have long-term and global benefits, whereas adaptation mostly has short-term, local and sector-specific benefits. ${ }^{3}$ For these reasons mitigation is typically mentioned prior to adaptation, not only on EU climate action websites ${ }^{4}$ but also in EU legislation, such as the 2020 Taxonomy Regulation, which con-

\footnotetext{
1 Proposal for a Regulation establishing the framework for achieving climate neutrality (European Climate Law), COM/2020/80 final. See also: https://ec.europa.eu/clima/policies/eu-climate-action/law_en accessed 16 January 2021.

2 D. Forster et al. (2017), Climate mainstreaming in the EU Budget: preparing for the next MFF, Luxembourg: Publications Office of the European Union, pp.7-8.

A. Hof, K. de Bruin, Rob Dellink, M. den Elzen and D. van Vuuren (2010), 'Costs, benefits and interlinkages between adaptation and mitigation', in: F. Biermann, P. Pattberg and F. Zelli (eds), Global Climate Governance Beyond 2012: Architecture, Agency and Adaptation. Cambridge: Cambridge University Press, pp.235-54.
}

4 See https://ec.europa.eu/clima/policies/eu-climate-action_en accessed 10 January 2021. 
tains criteria for sustainable investment. ${ }^{5}$ But there is also a fourth and more practical reason to focus on EU climate mitigation law: a textbook that covers both mitigation and adaptation in Europe would either be excessively long or would run the risk of insufficiently treating their respective legal characteristics and issues.

Most EU climate mitigation law comes in the form of EU directives and regulations that intend to reduce greenhouse gas emissions in the fight against climate change. These do not operate in isolation from other areas of EU law, such as energy law, environmental law, competition law, human rights law or financial regulation. We will touch upon those areas of law whenever they interact with EU climate mitigation law. Moreover, law is intended to have an impact on society. We will therefore pay some attention to the implementation of EU climate law and its effects on climate policy, companies and citizens.

Our book is the first textbook solely devoted to the basics of climate mitigation law in the EU, offering a thorough introduction for students, legal professionals and others who are unfamiliar with (some parts of) EU climate regulation. Our book, however, does more than that.

First, we focus on the relationship between climate law and the energy sector, because the use of energy is an important driver of climate change. The energy sector is responsible for the largest share of greenhouse gas emissions in the EU. ${ }^{6}$ These emissions are primarily the by-product of burning fossil fuels. Another reason for this focus is the explicit policy link made by the EU between climate and energy, for instance in the 2020 Climate and Energy Package and subsequently in the 2030 Climate and Energy Framework, adopted in 2008 and 2014 respectively. ${ }^{7}$ These policy documents outline the key climate and energy goals of the EU. They mainly contain interlinked targets for reducing greenhouse gas emissions by inter alia increasing the share of renewable energy and improving energy efficiency.

Second, after discussing the main climate targets and instruments of the EU, including emissions trading as well as the promotion of renewable energy and energy efficiency, we also expand upon some related issues, such as the impact of decarbonisation on energy network operations, multi-level governance and human rights. This is important to understand the broader picture of EU climate law. Promoting the use of renewable energy sources, for instance, requires investment in network expansion and the construction of new (types of) networks and has a clear impact on network balancing. Moreover, EU climate mitigation law is shaped in a process of multi-level governance between international climate agreements, EU climate policy and climate action by Member States as well as companies, cities and citizens. Last but not least, human rights play an increasingly important role in climate law, because climate change has a negative impact on people's fundamental rights, such as the right to life, the right to health and the right to a healthy environment. We are convinced that these broader issues deserve proper attention, because EU climate regulation does not develop in isolation but evolves with and adapts to interrelated legal issues.

Regulation (EU) 2020/852 on the establishment of a framework to facilitate sustainable investment, and amending Regulation (EU) 2019/2088 (Text with EEA relevance), PE/20/2020/INIT, OJ L 198, 22.6.2020, pp.13-43.

6 https://ec.europa.eu/eurostat/cache/infographs/energy/bloc-4a.html accessed 14 January 2021.

https://ec.europa.eu/clima/policies/strategies_en accessed 14 January 2021. 
The title of our book is Essential EU Climate Law - and not without reason. Focusing on the 'essence' of EU climate mitigation law means that we first (a) address the relevant directives and regulations and then continue to (b) analyse their implementation and (c) review current policy and academic debate on the climate targets and instruments of the EU. This combination is what makes our introduction a comprehensive one, namely by describing, analysing and reviewing the main features and issues of the EU legal framework that aims to combat climate change. The central question of our book is therefore: what is the essence of EU climate mitigation law?

The following sub-questions are addressed:

- What are the targets and instruments of EU climate mitigation law?

- What are the relevant directives and regulations in EU climate mitigation law?

- What are the main implementation issues of EU climate mitigation law?

- How can those implementation issues be solved in a cost-effective and acceptable way?

To ensure coherence and close coordination, all authors of our book are members or fellows of the Groningen Centre of Energy Law and Sustainability (GCELS), at the University of Groningen in the Netherlands. At the time of writing we were, and most of us still are, housed in the same Faculty building, although the COVID-19 pandemic forced us to work from home for some time. We agreed to write the core chapters on EU climate mitigation law based on a tight and uniform format that contained various requirements, not only in relation to issues of style, but also in relation to an analytical approach that consistently focuses on cost-effectiveness and solidarity in EU climate mitigation law. We will now elaborate upon this common approach.

\subsection{APPROACH OF THE BOOK}

Our approach is to explore the relevant legislation in each selected area of EU climate mitigation law from the perspective of the following two principles:

- cost-effectiveness, and

- solidarity.

The principles of cost-effectiveness and solidarity can already be found in the so-called 'Climate and Energy Package' proposal of 2008, in which the European Commission explains: ${ }^{8}$

The architecture of the proposals has been driven by two factors. First, the proposals are designed in such a way that the targets are reached in the most cost-effective way possible. Second, the effort required of particular Member States and particular industries remains

8 European Commission, 'Communication from the Commission to the European Parliament, the Council, the European Economic and Social Committee and the Committee of the Regions - 2020 by 2020: Europe's Climate Change Opportunity' (2008) $\operatorname{COM}(2008) 30$ final, 4. 
balanced and proportionate, and takes their own circumstances into account. Fairness and solidarity have been at the heart of the Commission's thinking in developing the proposals.

The same principles were also highlighted in 2014 in the European Council conclusions on the EU's climate and energy policy for $2030:^{9}$

The European Council endorsed a binding EU target of an at least $40 \%$ domestic reduction in greenhouse gas emissions by 2030 compared to 1990. To that end: [...] the target will be delivered collectively by the EU in the most cost-effective manner possible [and] all Member States will participate in this effort, balancing considerations of fairness and solidarity.

A wider set of principles but a comparable approach can be found in the European Commission's proposal, tabled in 2020, for a 'European Climate Law': ${ }^{10}$

A fixed long-term objective is crucial to contribute to economic and societal transformation, jobs, growth, and the achievement of the United Nations Sustainable Development Goals, as well as to move in a fair and cost-effective manner towards the temperature goal of the 2015 Paris Agreement on climate change [...] taking into account the importance of promoting fairness and solidarity among Member States.

The EU aims to reach its multiple climate targets by using various instruments that ensure least-cost implementation and solidarity among its Member States. Our main hypothesis, therefore, is that EU climate mitigation law is primarily based on the principles of cost-effectiveness and solidarity. This hypothesis is tested for the different areas of EU climate regulation in each separate chapter. This approach only applies to the second part of our book, which centres on essential EU climate mitigation law itself. It is not applied in the third part, which discusses overarching issues, such as energy network management, that relate only indirectly to EU climate law. An assessment based on these two principles allows for a characterisation of the relevant area of climate law that goes beyond a mere explanation of the law as it is. As a consequence, the author of each chapter in the second part of the book also answers the following question: to what extent have the principles of cost-effectiveness and solidarity been honoured in the relevant legislation, and what balance has been struck between them?

As part of this assessment, the role of other related issues, such as the protection of domestic economic interests, is also addressed. In some parts of EU climate law, the principle of solidarity may have gained ground at the expense of the principle of cost-effectiveness. In other parts of EU climate law, we would for instance expect that particular instruments orig-

\footnotetext{
$9 \quad$ European Council, 'European Council (23 and 24 October 2014) Conclusions on 2030 Climate and Energy Policy Framework' (2014) SN79/14, 2.

10 Proposal for a Regulation of the European Parliament and of the Council establishing the framework for achieving climate neutrality and amending Regulation (EU) 2018/1999 (European Climate Law), COM/2020/80 final, Preamble (3) and Article 2(2).
} 
inally intended to guarantee a cost-effective realisation of climate goals have been weakened to protect national industrial interests. This methodology gives the authors of the different chapters (in the second part of the book) a common writing approach to ensure consistency between the different chapters and to facilitate a critical analysis and review of the law.

\subsection{CONTRIBUTION OF THE BOOK}

This timely second, revised edition of our textbook offers a comprehensive introduction to EU climate law, with a special focus on the energy sector. We have updated our book based on the most recent legal developments. We have also made improvements based on a publisher survey among users of the first edition, including both lecturers and students. Alongside addressing the essential directives, regulations, decisions and court cases, our textbook analyses implementation issues, including their impact on cost-effectiveness and solidarity. The book reviews current policy and academic debate on EU targets and instruments to reduce greenhouse gas emissions. It also expands upon related legal issues, such as energy network regulation, multi-level governance and human rights. By focusing on the essence of EU climate mitigation law, it offers easily accessible insights for both students and professionals.

There are several books that deal with international and EU climate regulation or policy in one way or another. However, none of these books is solely devoted to the main features and implementation issues of EU climate mitigation law, with particular attention paid to the energy sector. There are several thematic books on climate law and policy, including very interesting books on climate change law in general, on EU Member State climate policies, on climate change adaptation law, on emissions trading, or on renewables, but none of these books provides a comprehensive introduction to essential EU climate law in relation to broader legal issues including energy law. This is what we aim to do.

Content-wise, in outlining the aforementioned subjects and issues, our book is unique. There is considerable academic literature on EU climate mitigation law dealing with very specific questions, but an up-to-date and easily accessible book that presents and critically reflects upon EU climate law was missing. As we focus on the relationship between climate mitigation and the energy sector, we will also examine specific energy-related climate mitigation developments, such as the regulation of carbon capture and storage (CCS), the promotion of renewable energy consumption and energy efficiency, as well as the decarbonisation of energy networks. Our book addresses this niche by targeting primarily students, but also others who need to familiarise themselves with EU climate law design and implementation in a comprehensive and time-efficient way.

Our book is unique in terms of process, too. Most of the chapters in the first edition were actively reviewed by students of the 2014 course on Climate Law at the University of Groningen. They provided valuable referee reports to us. This led to various questions and suggestions, on the basis of which we have been able to improve the chapters in our textbook. The second, revised edition has taken into account the most recent developments in EU climate mitigation law up to December 2020, as well as the outcomes of an EU-wide survey carried out by Edward Elgar Publishing in 2018 among users of the first edition of the book. 
Both lecturers and students from across Europe provided us with a useful 'wish list' which helped us to further improve our textbook. Examples are an extra chapter on the relationship between human rights and EU climate law, a new section on the role of cities in mitigating greenhouse gas emissions, more information on the use of carbon taxation and the addition of classroom questions to each chapter (with relevant legal issues to be debated in class), among others.

\subsection{OUTLINE OF THE BOOK}

Our book is organised as follows. The first part introduces the subject of, as well as our approach to, EU climate law. The purpose and approach of our book have been explained above. Chapter 2, which follows, gives an overview of EU climate policy, including a discussion on the impact that international climate law had on the development of EU climate measures. That chapter therefore presents a brief outline of the international, historical and policy background to EU climate mitigation law, as further explored in the second part of the book.

The chapters in the second part of the book describe and analyse the main pillars of EU climate regulation, focusing on the principles of cost-effectiveness and solidarity. We subsequently examine the EU's greenhouse gas emissions trading scheme, abbreviated as EU ETS (Chapter 3); the regulation of emissions from sectors not covered by the EU ETS (Chapter 4); and the roles of renewable energy consumption (Chapter 5), energy efficiency (Chapter 6) and carbon capture and storage (Chapter 7) in reducing greenhouse gas emissions, as well as the regulation of fluorinated gases (Chapter 8 ). These chapters provide more than just a concise overview of the relevant legislation. Starting with the basics and functioning of the applicable regulation, each chapter proceeds to explore key academic and policy debates and finishes with a brief outlook for the future.

The third part of the book explores the interaction between EU climate regulation and three important and topical overarching issues. First, we examine the legal consequences of EU climate regulation for the management of energy networks (Chapter 9). Among other things, we address how decentralised energy production impacts the existing regulatory framework that was designed for centralised energy systems, and how this leads to new and innovative legal solutions. We then discuss the issue of multi-level climate governance in the context of EU climate regulation (Chapter 10). In this chapter we examine the interaction between EU climate policies, on the one hand, and climate policies at the level of EU Member States and the international level, on the other. Subsequently, we discuss the relationship between human rights and EU climate law (Chapter 11). After clarifying the human rights obligations of the EU and its Member States when taking climate action, we explain why human rights-based climate litigation is emerging.

The fourth part of the book concludes. The final chapter reflects upon the past of EU climate law and provides an outlook on its possible future (Chapter 12). In this chapter we link the findings of the different chapters and give the reader some food for thought about the steps that the EU may or perhaps should take next to further improve its climate mitigation law. 
Before we start analysing the various aspects of EU climate mitigation law in the next chapters, we would like to make a comment on the science of climate change in relation to our book. In order to combat climate change, scientists want climate policies to lead to genuine reductions in greenhouse gas emissions. This must be done to limit the damage that these gases do. This damage is serious and increasingly visible, albeit surrounded by many uncertainties. There are climate sceptics and climate activists - and people that stand somewhere in between. It is not our intention to choose in favour of either of those sides. In fact, as lawyers and law and economics scholars, we lack the scientific knowledge to do so. We do observe that, according to the Intergovernmental Panel on Climate Change (IPCC), the balance of scientific evidence suggests a discernible human influence on the global climate. ${ }^{11}$ Instead of diving into the science of climate change and instead of choosing sides between sceptics and activists, the starting point of this book is a simple but clear legal observation. The EU and its Member States have - and this is a fact - formulated all kinds of policy targets as well as various legal and regulatory instruments to reduce greenhouse gas emissions. We take it from there, and describe, analyse and review these targets and instruments in EU climate mitigation law.

\subsection{ACKNOWLEDGEMENTS}

This book was initiated by Marijn Holwerda, a specialist in carbon capture and storage who obtained his doctoral degree at the Faculty of Law in Groningen. At the University of Groningen, Martha Roggenkamp is a specialist in energy law and coordinates several teaching programmes such as the LLM in Energy and Climate Law. Edwin Woerdman is a specialist in emissions trading and coordinates several courses, including the master course on Climate Law. Together they form the editorial team of this book. Each chapter in this book has been refereed by two members of this editorial team. Most of the chapters of the first edition have also been reviewed by students of the 2014 course on Climate Law at the University of Groningen. The second, revised edition was improved based on a 2018 review carried out among lecturers and students throughout Europe. The chapters themselves were written by the following members or fellows of GCELS:

- Chapter 1 Edwin Woerdman, Martha Roggenkamp and Marijn Holwerda

- Chapter 2 Florian Stangl and Romain Mauger

- Chapter 3 Edwin Woerdman

- Chapter 4 Lorenzo Squintani

- Chapter 5 Olivia Woolley

11 'Human activities are estimated to have caused approximately $1.0^{\circ} \mathrm{C}$ of global warming above pre-industrial levels, with a likely range of $0.8^{\circ} \mathrm{C}$ to $1.2^{\circ} \mathrm{C}$. Global warming is likely to reach $1.5^{\circ} \mathrm{C}$ between 2030 and 2052 if it continues to increase at the current rate. [...] Climate-related risks to health, livelihoods, food security, water supply, human security, and economic growth are projected to increase with global warming of $1.5^{\circ} \mathrm{C}$ and increase further with $2^{\circ} \mathrm{C}$.' Quotation taken from: IPCC Special Report (2018), Global Warming of $1.5^{\circ} \mathrm{C}$ : Summary for Policymakers, V. Masson-Delmotte et al. (eds.), Geneva: World Meteorological Organization, p.4 and p.9. 
- Chapter 6 Hans Vedder

- Chapter 7 Marijn Holwerda and Joris Gazendam

- Chapter 8 Kars de Graaf and Hanna Tolsma

- Chapter 9 Martha Roggenkamp and Lea Diestelmeier

- Chapter 10 Hans Vedder

- Chapter 11 Marlies Hesselman

- Chapter 12 Edwin Woerdman, Martha Roggenkamp and Marijn Holwerda

In the first edition, Avelien-Haan Kamminga was co-author of the chapter on carbon capture and storage (now Chapter 7), and Hannah Kruimer was co-author of the chapter on energy network management (now Chapter 9). Although they are not involved in this second edition, we do want to thank them sincerely for their hard work in preparing the first edition a few years ago. 